\title{
Expression changes of hippocampal energy metabolism enzymes contribute to behavioural abnormalities during chronic morphine treatment
}

\author{
Xiao-Lan Chen ${ }^{1}$, Gang Lu ${ }^{1}$, Ying-Xia Gong ${ }^{2}$, Liang-Cai Zhao ${ }^{3}$, Jie Chen ${ }^{1}$, Zhi-Qiang Chi $^{1}$, Yi-Ming Yang ${ }^{1}$, Zhong \\ $\mathrm{Chen}^{2}$, Qing-lin $\mathrm{Li}^{3}$, Jing-Gen Liu ${ }^{1}$ \\ ${ }^{1}$ State key Laboratory of Drug Research, Shanghai Institute of Materia Medica, Shanghai Institutes for Biological Sciences, Chinese \\ Academy of Sciences, Shanghai 201203, China; ${ }^{2}$ Department of Pharmacology, School of Medicine, Zheijiang University, Hangzhou \\ 310031, China; ${ }^{3}$ Department of Pharmacology, Anhui University of Traditional Chinese Medicine, Hefei 230032, China
}

Dependence and impairment of learning and memory are two well-established features caused by abused drugs such as opioids. The hippocampus is an important region associated with both drug dependence and learning and memory. However, the molecular events in hippocampus following exposure to abused drugs such as opioids are not well understood. Here we examined the effect of chronic morphine treatment on hippocampal protein expression by proteomic analyses. We found that chronic exposure of mice to morphine for 10 days produced robust morphine withdrawal jumping and memory impairment, and also resulted in a significant downregulation of hippocampal protein levels of three metabolic enzymes, including Fe-S protein 1 of NADH dehydrogenase, dihydrolipoamide acetyltransferase or E2 component of the pyruvate dehydrogenase complex and lactate dehydrogenase 2 . Further real-time quantitative PCR analyses confirmed that the levels of the corresponding mRNAs were also remarkably reduced. Consistent with these findings, lower ATP levels and an impaired ability to convert glucose into ATP were also observed in the hippocampus of chronically treated mice. Opioid antagonist naltrexone administrated concomitantly with morphine significantly suppressed morphine withdrawal jumping and reversed the downregulation of these proteins. Acute exposure to morphine also produced robust morphine withdrawal jumping and significant memory impairment, but failed to decrease the expression of these three proteins. Intrahippocampal injection of D-glucose before morphine administration significantly enhanced ATP levels and suppressed morphine withdrawal jumping and memory impairment in acute morphine-treated but not in chronic morphine-treated mice. Intraperitoneal injection of high dose of D-glucose shows a similar effect on morphine-induced withdrawal jumping as the central treatment. Taken together, our results suggest that reduced expression of the three metabolic enzymes in the hippocampus as a result of chronic morphine treatment contributes to the development of drug-induced symptoms such as morphine withdrawal jumping and memory impairment.

Keywords: hippocampus, glucose, morphine, dependence, learning and memory

Cell Research (2007) 17:689-700. doi: 10.1038/cr.2007.63; published online 31 July 2007

\section{Introduction}

The two well-established adverse effects of opioids are dependence and impairment of learning and memory. Dependence is manifested by a withdrawal syndrome

Correspondence: Jing-Gen Liu

Tel: +86-21-50807588; Fax: 86-21-50807088

E-mail: jgliu@mail.shcnc.ac.cn

Received 6 March 2007; revised 23 March 2007; accepted 10 April 2007; published online 31 July 2007 typically observed after the cessation of drug administration or precipitation with an antagonist such as naloxone (physical dependence), and by a compulsive drug seeking and taking behaviour (psychological dependence) [1]. Both acute and chronic exposures to morphine lead to physical dependence [2-4]. Impairment of learning and memory is shown as poor performances on memory task in human heroin users [5] and opioid-treated rodents [6-8]. Acute or chronic exposure to morphine impairs the function of learning and memory [6, 7]. Long-term potentiation (LTP) is the well-established cellular model of learning and memory, 
and chronic morphine treatment significantly inhibits LTP in rat hippocampus [8]. Recently, it has been proposed that common neurobiological mechanisms and same molecular and cellular events might contribute to drug addiction and the associated learning and memory impairment [9].

The hippocampus is a brain region associated with learning and memory [10]. Increasing evidence demonstrates that it also plays an essential role in opioid dependence. For instance, it has been reported that the hippocampus is functionally involved in morphine-induced conditioned place preference [11-13] and withdrawal behaviours [1416]. Additionally, it also plays a role in cocaine-seeking behaviour [17] as well as in alcohol tolerance [18]. Thus, the hippocampus appears to be an important region associated with both drug dependence and learning and memory. However, the molecular events occurring in the hippocampus following exposure to abused drugs such as opioids are poorly understood.

Attenuation of several enzyme activities in cell intermediary metabolism such as glycolysis and the tricarboxylic acid (TCA) cycle has been observed in the brain of opiateabusing patients and opiate dependent animals [19-21]. It has also been reported that systemic or intrahippocampal injection of glucose or its metabolite pyruvate attenuates acute morphine-induced memory impairment and increment of locomotor activity [6, 22-25]. In addition, glucose has also been shown to suppress acute morphine withdrawal signs in rodents and in guinea-pig ileum [26-28]. These findings suggest that opioid-induced dependence and memory deficits may be partially attributed to the impairment of hippocampal glucose metabolism as a sequel to attenuation of metabolic enzyme activities.

Opiate dependence is associated with long-term adaptive changes in the brain, which may involve alterations of gene and protein expression in certain brain areas [29]. This study, therefore, was undertaken to examine the effect of chronic morphine treatment on hippocampal protein expression using proteomic analysis and determine whether downregulation of expression of hippocampal energy metabolism enzymes was involved in opiate dependence and associated impairment of learning and memory.

\section{Materials and Methods}

\section{Animal treatment and morphine withdrawal jumping}

Kunming strain male mice (18-22 g) were obtained from Experimental Animal Centre, Chinese Academy of Sciences (Shanghai, China). Mice were housed in groups and maintained on a $12 \mathrm{~h} \mathrm{light/dark}$ cycle at $22-24{ }^{\circ} \mathrm{C}$ with food and water available ad libitum. Studies were carried out in accordance with the Guide for Care and Use of laboratory Animals as adopted by the National Institutes of Health. Acute morphine dependence was induced by a single subcutaneous injection of morphine $(100 \mathrm{mg} / \mathrm{kg})$. Chronic morphine dependence was rendered by subcutaneous injection of morphine twice daily at $8 \mathrm{~h}$ intervals for 10 days as described previously [30]. One group of mice was treated concomitantly with morphine and naltrexone (4 $\mathrm{mg} / \mathrm{kg}$, i.p.). Naltrexone was injected $30 \mathrm{~min}$ before each morphine injection. Control mice were treated similarly, except that normal saline was used as a substitute for morphine and naltrexone. For assessment of dependence, withdrawal jumping was precipitated by subcutaneous injection of naloxone $(2 \mathrm{mg} / \mathrm{kg}) 2 \mathrm{~h}$ following a single (acute) or final (chronic) morphine injection. The jumping frequency of each mouse and the number of mice that jumped in each group within 20 min were recorded. The positive jumping response was defined as jumping more than four times in $20 \mathrm{~min}$. For examination of the effect of glucose on acute and chronic dependence, glucose was intraperitoneally (200 to $1000 \mathrm{mg} / \mathrm{kg}$ ) or intrahippocampally ( $8 \mathrm{nmol}$ per side) injected before single or final morphine injection. For proteomic, mRNA and ATP analysis, animals were killed by decapitation $1 \mathrm{~h}$ after a single or final morphine injection. The hippocampus was isolated, frozen in liquid nitrogen and then stored at $-80^{\circ} \mathrm{C}$ until used.

\section{Intrahippocampal injection of glucose}

Mice were anaesthetized with sodium pentobarbital $(35 \mathrm{mg} / \mathrm{kg}$, i.p.), and fixed on a stereotaxic apparatus (SR-5, Narishige, Tokyo, Japan) with mouse adapter and lateral bars. A guide cannulae $(0.5$ $\mathrm{mm}$ outer diameter) made of stainless steel tubing was implanted into the bilateral hippocampus according to the following coordinates measured from bregma: AP: $-2.8 \mathrm{~mm}, \mathrm{~L}: \pm 2.5 \mathrm{~mm}$ and $\mathrm{H}: 1.8 \mathrm{~mm}$ from the skull [31]. At least 7 days were allowed for recovery from the surgery. Correct placement of cannulae was verified after the experiment. Infusion cannulae $(0.25 \mathrm{~mm}$ diameter $)$ were gently inserted into the guide cannulae. The injector was connected with a polyethylene catheter tubing to a $1-\mu 1$ Hamilton syringe driven by a microinjection pump at a rate of $0.1 \mu \mathrm{l} / \mathrm{min}$. Injection of glucose ( $8 \mathrm{nmol}$ in $0.2 \mu \mathrm{laCSF}$ (artificial cerebrospinal fluid) per side) or aCSF $(0.2 \mu \mathrm{l}$ per side) were performed in freely moving mice at a perfusion rate of $0.2 \mu \mathrm{l} / \mathrm{min}$. To allow diffusion of drug, the infusion cannulae were left in place $1 \mathrm{~min}$ following the injection [32].

\section{Morris water maze test}

This test was performed as previously described [7]. Briefly, a circular pool (diameter $110 \mathrm{~cm}$, height $40 \mathrm{~cm}$ ) was filled to a depth of $20 \mathrm{~cm}$ with water. The water was maintained at $20 \pm 0.5^{\circ} \mathrm{C}$ and made opaque by the addition of $15-\mathrm{ml}$ India ink. Four equally spaced points around the edge of the pool were designed as four starting positions: east (E), south (S), west (W) and north (N). An escape platform (diameter $6.5 \mathrm{~cm}$ ) was submerged $1 \mathrm{~cm}$ below water surface and placed in the centre of the south and west quadrant. The mouse in the pool was trained to find the platform. Each mouse was trained four times each day. The latency to find the escape platform was measured during each trial. Upon finding and climbing the platform, the mice stayed there for $20 \mathrm{~s}$. If the mice failed to find the platform within $60 \mathrm{~s}$, they were placed on the platform by experimenter and a maximum score of $60 \mathrm{~s}$ was given. After rest for $20 \mathrm{~s}$ on the platform, the next trial was initiated. For assessment of the effect of glucose or 3-O-methyl-glucose on acute morphine-induced impairment of learning and memory, the task was performed consecutively for 5 days. From day 1 to day 4, each mouse received two injections of saline daily before the training. On the test day, glucose (500 $\mathrm{mg} / \mathrm{kg}$, i.p.) or 3-O-methyl-glucose $(500 \mathrm{mg} / \mathrm{kg}$, i.p. $)$ was injected 
$2 \mathrm{~h}$ before morphine injection. Escape latency of each mouse was recorded $20 \mathrm{~min}$ after morphine injection $(10 \mathrm{mg} / \mathrm{kg}$, s.c.). For test of the effect of glucose on chronic morphine-induced cognitive deficits, mice were chronically treated with morphine for 10 days as described above, and were trained $20 \mathrm{~min}$ after second injection of morphine or saline every day. Glucose $(500 \mathrm{mg} / \mathrm{kg}$, i.p.) was given $2 \mathrm{~h}$ before the last morphine injection. Escape latency of each mouse was recorded 20 min after a single (acute) or final (chronic) morphine injection. To determine the effect of morphine on mice swimming ability and visual discrimination, the swimming time for mice to climb onto the platform was also recorded when the platform was set in a pool filled with clear water to the depth of $20 \mathrm{~cm}$ and made visible by mounting a blue-coloured picture on it.

\section{Sample preparation and two-dimensional gel electrophore-} sis

Frozen samples of the hippocampus were homogenized in $400 \mu \mathrm{l}$ lysis solution containing $8 \mathrm{M}$ urea, 4\% CHAPS (Bio-Rad, Hercules, CA), $100 \mathrm{mM}$ DTT and 2\% Ampholyte 3-10 (Bio-Rad, Hercules, CA), and then centrifuged at $20000 \times g$ for $2 \mathrm{~h}$ at $4{ }^{\circ} \mathrm{C}$. The supernatants were stored in aliquots at $-80{ }^{\circ} \mathrm{C}$ until analysed and the protein concentration in supernatant was determined by the Bradford method. Two-dimensional gel electrophoresis (2-DE) was performed as previously reported [33]. Samples of $150 \mu \mathrm{g}$ protein were applied on $17 \mathrm{~cm}$ immobilized $\mathrm{pH}$ 4-7 linear gradient strips (Bio-Rad, Hercules, CA). Isoelectric focusing starts at $100 \mathrm{~V}$ for $30 \mathrm{~min}$ and gradually increased to $5000 \mathrm{~V}$ and kept constant for $12 \mathrm{~h}$. After IEF, the strips were equilibrated twice for $15 \mathrm{~min}$ with gently shaking in a solution of Tris- $\mathrm{HCl}$ buffer $(50 \mathrm{mM}, \mathrm{pH} 6.8)$, urea $(6 \mathrm{M})$, glycerol $(30 \%, \mathrm{w} / \mathrm{v})$, SDS (2\%, w/v) and DTT (2\% w/v). DTT was replaced with $2.5 \% \mathrm{w} / \mathrm{v}$ iodoacetamide (Fluka, Buchs, SG) in the second equilibration. After equilibration, the IPG strips were placed on top of the SDS-polyacrylamide gels $(12 \% \mathrm{~T} ; 0.32 \% \mathrm{C})$ (Sigma St. Louis, MO). The gels $(180 \times 200 \times 1.5 \mathrm{~mm})$ were run at $40 \mathrm{~mA}$ per gel, in the vertical Protean II Xi cell (Bio-rad, USA) at $10{ }^{\circ} \mathrm{C}$. Then the gels were silver stained according to the method [34]. Molecular masses were determined by running standard protein markers, covering the range of $14-66 \mathrm{kDa}$. The $\mathrm{pI}$ values were used as given by the supplier of the IPG strips. The silver-stained gels were scanned using a GS-800 Calibrated Imaging Densitometer (Bio-Rad, Hercules, CA) in transmission mode. The protein spots were detected, quantified and matched using the PD-Quest 2D-gel analysis software, Version 7.1 (Bio-Rad, Hercules, CA). The protein spots from different gels were matched and their volumes were determined. The integrated intensities of all spots appearing on the control and morphine master images were compared. Only the spots of which the integrated intensity differed by at least two-fold were statistically analysed and proteins with levels altered significantly $(p<0.05)$ in the morphine-treated mice as compared to control were reported. Altered proteins were cut out for identification.

\section{In-gel digestion and mass spectrometry}

Silver-stained protein bands were excised, destained by $1 \% \mathrm{H}_{2} \mathrm{O}_{2}$ in $25 \mathrm{mM}$ ammonium bicarbonate, $\mathrm{pH} 8.5$, followed by reduction and alkylation as previously described [35]. In-gel trypsin digestion $\left(300 \mathrm{ng}\right.$ ) was allowed at $37^{\circ} \mathrm{C}$ for $18 \mathrm{~h}$. Tryptic peptides were subsequently extracted using three cycles of $5 \%$ formic acid $/ 50 \%$ acetonitrile at $37{ }^{\circ} \mathrm{C}$ for $1 \mathrm{~h}$ each. LC-MS/MS analysis was performed using a Micromass Q-TOF Ultima Global (Micromass,
Manchester, UK) in electrospray mode interfaced with an Agilent HP1100 CapLC (Agilent Technologies, Palo Alto, CA) before the mass spectrometer. Five millilitres of each digest was loaded onto a Vydac C18 MS column $(100 \times 0.15$ mm; Grace Vydec, Hesperia, CA) and chromatographic separation was performed at $1 \mathrm{il} / \mathrm{min}$ using the following gradient: $0-10 \%$ B over 5 min; gradient from 10 to $40 \%$ B over $60 \mathrm{~min}$; from $40 \%$ to $95 \%$ B over 5 min; $95 \%$ B held over 5 min (solvent A: $0.2 \%$ formic acid in water; solvent B: $0.2 \%$ formic acid in acetonitrile). Data-dependent analysis (DDA) method collected tandem MS/MS data for the three most abundant peptide ions observed in the preceding survey scan $(\mathrm{m} / \mathrm{z}$ 300-1990) above a threshold of 10 counts/s. Data were processed using the MassLynx software package (version 4.0) to generate peak list files before in-house licensed Mascot search [36] at http://biospec.nih. gov (MatrixScience Ltd, London, UK).

\section{Real-time quantitative polymerase chain reaction}

RNA was extracted from the hippocampus harvested from six chronic morphine-treated mice and from six saline-treated mice using TRIzol reagent (Invitrogen, Carlsbad, CA) according to the manufacturer's protocol. Oligo (dT)-primed first-strand cDNA synthesis was performed with kit for RT-PCR (M-MLV) (Promega, Madison, WI) using $2 \mu \mathrm{g}$ of total RNA as a template in a total volume of $25 \mu \mathrm{l}$. Reaction conditions were set up as described by the manufacturer's manual. The thermal cycling conditions were $94{ }^{\circ} \mathrm{C}$ for $2 \mathrm{~min}$, followed by 35 cycles, each consisting of $94{ }^{\circ} \mathrm{C}$ for $30 \mathrm{~s}$ for melting, $60{ }^{\circ} \mathrm{C}$ for $30 \mathrm{~s}$ for annealing, and $72{ }^{\circ} \mathrm{C}$ for $30 \mathrm{~s}$ extension. Experimental samples, standards and no-template controls were all run in triplicate. For quantification of RNA targets, QuantiTect SYBR Green RT-PCR was used, containing SYBR Green I as a fluorescent dye. Specificity of RT-PCR products was verified by checking the product melting curves (every time). To further ascertain the specificity and size of PCR products, the products were run on $2 \%$ agarose gel with molecular weight marks. The gel was stained with ethidium bromide.

The primers were designed from the sequences in the GenBank database using Primer Express software (Perkin-Elmer, Boston, MA). The followings are the sequences of primers:

LDH2: forward 5'-TCTGCTCGATTCCGCTAC-3', reverse 5'CACCTCCTTCCAGTTCTCAC-3';

Fe-S protein 1 of NADH dehydrogenase: forward 5'-TCATTCTGCGAGGTCTTA-3', reverse 5'-ATAGCCAAGGTCCAAAGC-3'; PDHC-E2: forward 5'-TCCAAAGCGAGAGAGGGTAA-3', reverse 5'-AGCACCGATTGCCAGAATAC-3';

$\beta$-actin (as a housekeeping gene): forward 5'-TTCTTTGCAGCTCCTTCG-3', reverse 5'-TTCTGACCCATTCCCACC -3'.

All the primers were synthesized by Boya (Boya, Shanghai).

\section{ATP determination}

ATP levels of the hippocampus derived from different treatment mice were determined using the Bioluminescence detection kit (Promega, USA), according to the manufacturer's instruction. The samples of the hippocampus were weighted, and then grinded in $0.4 \mathrm{M}$ perchlorid acid $(10 \mu \mathrm{l} / \mathrm{mg}$ wet weight $)$ and centrifuged (10 $000 \mathrm{rpm}$ for $10 \mathrm{~min}$ ). Supernatants were collected and neutralized to $\mathrm{pH} 7.8$ with $2 \mathrm{M} \mathrm{K}_{2} \mathrm{CO}_{3}$ and centrifuged (10 $000 \mathrm{rpm}$. for $10 \mathrm{~min}$. Samples were then 1000 -fold diluted in distilled water and $180 \mu \mathrm{l}$ aliquot was added to wells of a 96-well reaction plate. This plate was loaded into the luminometer (Polar star galaxy) and 
$20 \mu \mathrm{l}$ of the $\mathrm{rL} / \mathrm{L}$ Reagent were added to each well by means of an injection pump, and the samples were measured. Immediately after addition of the rL/L Reagent, ATP was monitored over a period of $10 \mathrm{~s}$. ATP concentration was calculated according to an ATP standard curve (from $10^{-11}$ to $10^{-7} \mathrm{M}$ ). Data are expressed using the relative concentrations of ATP.

\section{Statistical analysis}

Data are presented as means \pm SEM of at least three independent experiments. Statistical difference between treatment groups was analysed by one-way ANOVA followed by Newman-Keuls test or Student's $t$-test.

\section{Results}

Decreased expression of $\mathrm{Fe}$-Sprotein 1 of NADH dehydrogenase, PDHC-E2 and LDH2 in chronic morphine-treated mouse hippocampus

The hippocampal extracts from control (saline treated), acute and chronic morphine-treated mice were separated by $2-\mathrm{DE}$ followed by silver staining. Proteins displaying altered levels were quantified from the 2-DE gels using PDQuest software and identified by Q-TOF mass spectrometer. 2-DE separation and silver staining revealed that there were 1240 spots in the gel of hippocampal sample of salinetreated mice (Figure 1, upper panel to Figure 1A). A similar pattern of protein expression was detected in the hippocampal sample of chronic morphine-treated mice (Figure 1, lower panel to Figure 1B). Most spots were distributed at positions between $\mathrm{pH} 4$ and 7, and with molecular weights between 20 and $100 \mathrm{kDa}$. Comparison of the intensity of protein spots between chronic morphine- and saline-treated mice indicated that seven proteins were decreased and one was increased significantly $(p<0.05)$ in the hippocampus from chronic morphine-treated mice (Table 1).

Interestingly, among the seven proteins that were significantly decreased, three were identified as energy metabolism enzymes, namely Fe-S protein 1 of NADH dehydrogenase, dihydrolipoamide acetyltransferase or E2 component of the pyruvate dehydrogenase complex (PDHC-E2) and lactate dehydrogenase 2 (LDH2) (Figure 2; Table 2). Similar to the hippocampus from saline-treated mice, changes in the expression of these proteins were not observed in the hippocampus from mice that were subjected to a single acute injection with a dose of $100 \mathrm{mg} / \mathrm{kg}$ of morphine (data not shown). To address whether the downregulation of the expression of these three proteins (Fe-S protein 1 of NADH dehydrogenase, PDHC-E2 and LDH2) was mediated by opioid receptors, the effect of opioid receptor antagonist naltrexone ( $4 \mathrm{mg} / \mathrm{kg}$, i.p.) was examined. As expected, administration of naltrexone before each morphine injection prevented morphine-mediated decrease in the expression of these three proteins (Figure 3).
Reduced levels of mRNAs of Fe-S protein 1 of NADH dehydrogenase, PDHC-E2 and LDH2 in chronic morphinetreated mouse hippocampus

To further confirm the proteomic analysis results and to examine the underlying mechanisms of reduced expression of these three proteins, we determined whether the levels of the corresponding mRNAs of these proteins were affected by chronic morphine treatment, using quanitative real time RT-PCR. Figure 4A shows the detection of specific RT-PCR products on an agarose gel, and the specificity was further validated by constructing a melting temperature curve (data not shown). Our results showed that the transcripts for $\mathrm{Fe}-\mathrm{S}$ protein 1 of NADH dehydrogenase, PDHC-E2 and LDH2 were significantly decreased (by 1.86-, 1.67- and 1.56-fold respectively) in the hippocampus of chronic morphinetreated mice as compared to saline-treated control. Taken together, the results of our protein and mRNA analyses support the notion that chronic morphine treatment leads to reduced expression of these three metabolic enzymes (Fe-S protein 1 of NADH dehydrogenase, PDHC-E2 and LDH2).

Reduction of ATP production and impairment of glucose metabolism in the hippocampus of chronic but not acute morphine-treated mice

Fe-S protein 1 of NADH dehydrogenase, PDHC-E2 and $\mathrm{LDH} 2$ are associated with energy metabolism and ATP production. To further substantiate the results from the proteomic analysis, we examined glucose metabolism and ATP levels in the hippocampus from control, acute and chronic morphine-treated mice. As shown in Figure $5 \mathrm{~A}$, the levels of ATP in the hippocampus from chronic morphine-treated mice were significantly lower than that in the saline-treated control, suggesting that energy metabolism was impaired in the hippocampus of chronic morphine-treated mice. The reduction of ATP production by chronic morphine treatment could be prevented by concomitant administration of naltrexone. In contrast, significant reduction of ATP levels was not observed in the hippocampus from acute morphine-treated mice (Figure $5 \mathrm{~A}$, left panel). Intraperitoneal injection of D-glucose $(200 \mathrm{mg} / \mathrm{kg})$ significantly increased ATP levels in the hippocampus from acute morphine-treated mice but not from chronic morphine-treated mice (Figure 5B), further suggesting the impairment of glucose metabolism in the hippocampus of chronic morphine-treated mice. Intraperitoneal injection of the same dose of 3-O-methyl-glucose, a non-metabolizable sugar, failed to increase ATP levels in the hippocampus from acute morphine-treated mice (Figure 5B), suggesting that glucose metabolism is necessary for the observed increase of ATP levels. Taken together, these results suggest that downregulation of $\mathrm{Fe}-\mathrm{S}$ protein 1 of 

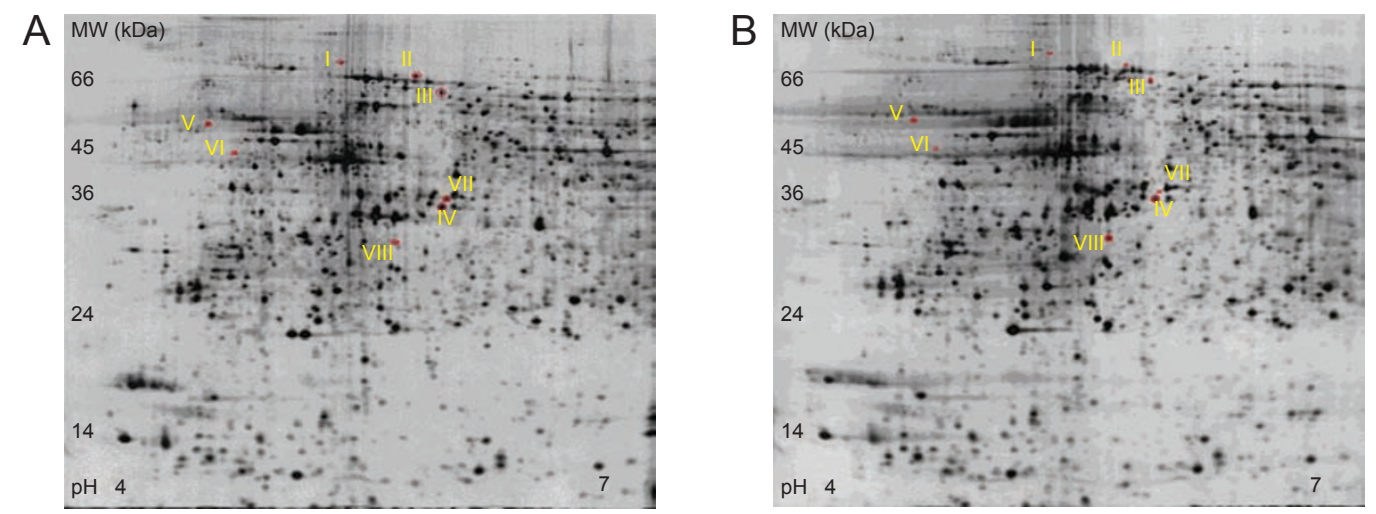

Figure 1 Representative 2-DE gel images of the hippocampal proteins from mice differentially treated with saline (A) or morphine (B). Mice were treated with saline or an increasing dose (from 20 to $100 \mathrm{mg} / \mathrm{kg}$, s.c.) of morphine for 10 days. Hippocampal protein $(150 \mu \mathrm{g})$ was separated on PH 4-7 linear IPG strips $(170 \mathrm{~cm})$ followed by separation on 12\% SDS-PADE gels as described in Materials and Methods. The gels were visualized using silver staining. The samples for 2-DE were prepared from hippocampus of nine mice. The horizontal dimension represents a PH gradient of 4-7, and the vertical dimension is indicated by molecular markers. Labelled spots (A-C) are proteins that were differentially expressed in the hippocampus from mice differentially treated with saline or morphine.

Table 1 Eight differentially expressed proteins between chronic saline- and morphine-treated mice

\begin{tabular}{lllllc}
\hline \multirow{2}{*}{ Spot no. } & Observed pI/ & \multicolumn{2}{c}{ Abundance } & & \multirow{2}{*}{ Folds of changes } \\
\cline { 2 - 4 } & Mr (kDa) & Control & Morphine & & \\
\hline I & $5.5 / 79$ & $0.054 \pm 0.015$ & $0.018 \pm 0.018$ & -3.00 & 0.009 \\
II & $5.9 / 73$ & $0.170 \pm 0.047$ & $0.048 \pm 0.025$ & -3.54 & 0.001 \\
III & $5.7 / 59$ & $0.437 \pm 0.075$ & $0.170 \pm 0.059$ & -2.57 & 0.001 \\
IV & $5.7 / 36$ & $0.277 \pm 0.177$ & $0.083 \pm 0.073$ & -3.37 & 0.035 \\
V & $4.5 / 58.6$ & $0.063 \pm 0.012$ & $0.030 \pm 0.012$ & -2.11 & 0.019 \\
VI & $4.7 / 49.7$ & $0.040 \pm 0.010$ & $0.010 \pm 0.000$ & -4.00 & 0.007 \\
VII & $5.9 / 38.4$ & $0.127 \pm 0.012$ & $0.037 \pm 0.021$ & -3.45 & 0.003 \\
VIII & $5.6 / 30.0$ & $0.043 \pm 0.021$ & $0.101 \pm 0.025$ & & +2.52 \\
\hline
\end{tabular}

The silver-stained gels were scanned using a GS-800 Calibrated Imaging Densitometer in transmission mode. The protein spots were matched using the PD-Quest 2D-gel analysis software, and only the spots of which the integrated intensity differed by at least two-folds were statistically analysed. The integrated intensities of these spots appearing on the control and morphine images were compared. $201 \times 121$ $\mathrm{mm}(72 \times 72 \mathrm{DPI})$.

complex I, PDHC-E2 and LDH2 in the hippocampus of chronic morphine-treated mice leads to a decrease of ATP production due to impaired glucose metabolism.

Intrahippocampal injection of D-glucose suppressed naloxone-precipitated morphine withdrawal jumping in acute but not chronic morphine-treated mice

To determine the role of impaired hippocampal glucose metabolism in morphine dependence, we next examined the effect of intrahippocampal glucose administration on naloxone-precipitated morphine withdrawal jumping in both acute and chronic morphine-treated mice. Among withdrawal behaviours in opiate dependence rodents (es- pecially, mice), jumping is widely considered as the most sensitive and reliable index and is commonly used to test opiate dependence state [2]. In agreement with previous studies [2-4], both acute and chronic treatment of mice with morphine induced a robust withdrawal jumping following naloxone precipitation, and this effect could be significantly suppressed by concomitant administration of naltrexone with morphine (Figure 6).

Next, the effects of glucose administration on acute and chronic morphine-induced withdrawal jumping were determined. Intrahippocampal injection of D-glucose $(8 \mathrm{nmol}$ per side) before morphine administration significantly reduced the numbers of jumping mice and jumping frequency of 
A

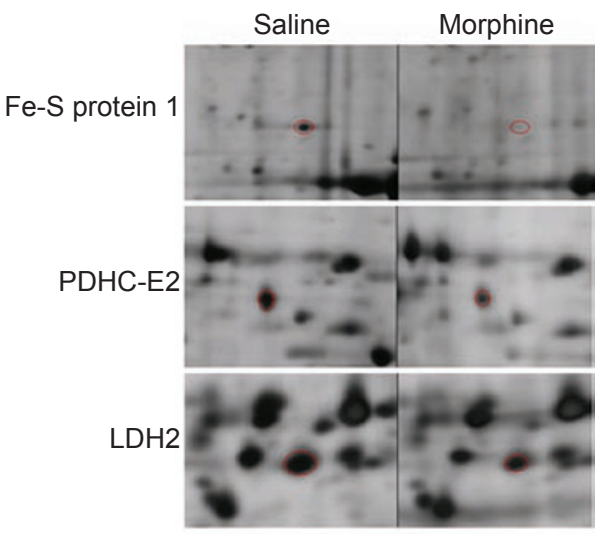

B

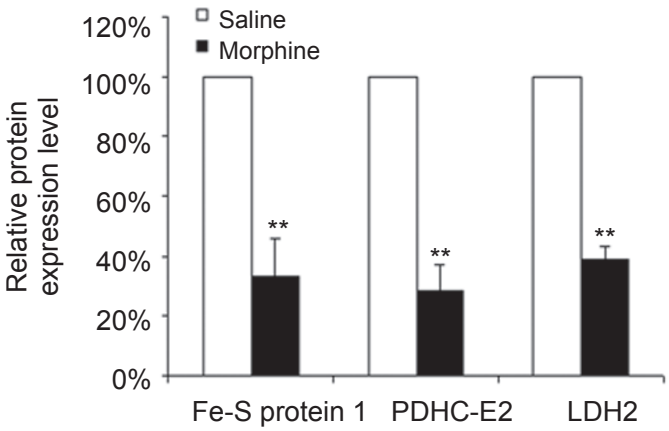

Figure 2 Decreased expression of Fe-S protein 1 of NADH dehydrogenase, PDHC-E2 and LDH2 in the hippocampus from mice chronically treated with morphine. (A) 2-DE images of the hippocampal proteins derived from the saline-, and chronic morphinetreated mice. (B) Quantification of the alterations of protein expression between the two groups. Mice were treated with saline or an increasing dose (from 20 to $100 \mathrm{mg} / \mathrm{kg}$, s.c.) of morphine for 10 days. The hippocampus extracts from mice differentially treated with saline or morphine were separated by 2-DE followed by silver staining. Protein levels were quantified using PD-Quest software. Data are presented as means \pm SEM of at least three separate experiments $(n=9) .{ }^{* *} p<0.01$ versus saline-treated mice.

Table 2 Identification of the proteins differentially expressed between saline- and morphine-treated mouse hippocampus by mass spectrometry

\begin{tabular}{|c|c|c|c|c|c|}
\hline Spot no. & Proteins identified & $\begin{array}{l}\text { Accession } \\
\text { no. NCBI }\end{array}$ & $\begin{array}{l}\text { Theoretical pI } \\
/ \mathrm{Mr}(\mathrm{kDa})\end{array}$ & $\begin{array}{l}\text { Mascot total } \\
\text { MOWSE }\end{array}$ & Identified peptides \\
\hline I & Fe-S protein 1 & 21704020 & $5.5 / 79$ & 75 & $\begin{array}{l}\text { SATYVNTEGRFASEIAGV } \\
\text { DDLGTTGR } \\
\text { ALSEIAGITLPYDTLDQVR }\end{array}$ \\
\hline III & PDHC-E2 & 16580128 & $5.7 / 59$ & 167 & $\begin{array}{l}\text { ILVPEGTR } \\
\text { VFVSPLAK } \\
\text { DIDSFVPSK } \\
\text { GLETIASDVVSLASK }\end{array}$ \\
\hline IV & LDH2 & 6678674 & $5.7 / 36$ & 168 & $\begin{array}{l}\text { LNLVQR } \\
\text { IVVVTAGVR } \\
\text { GLTSVINQK } \\
\text { VIGSGC*NLDSAR }\end{array}$ \\
\hline
\end{tabular}

Fe-S protein 1 = Fe-S protein 1 of NADH dehydrogenase; PDHC-E2 = E2 component of the pyruvate dehydrogenase complex; LDH2 = lactate dehydrogenase 2. Silver-stained protein bands were excised, trypsinized, extracted and analysed with Q-TOF mass spectrometer as described in Materials and Methods. Data were processed using the MassLynx software package to generate peak list files before in-house licensed Mascot search.

each mouse in acute morphine-treated groups (Figure 6A). However, intrahippocampal injection of D-glucose failed to inhibit naloxone-precipitated morphine withdrawal jumping in chronic morphine-treated mice (Figure 6B). We also examined the effect of the non-metabolizable sugar 3-O-methyl-glucose, and found that intrahippocampal injection of the same dose of 3-O-methyl-glucose was unable to inhibit morphine withdrawal jumping in acute morphine-treated mice (Figure 6A). These results suggest that normal energy metabolism is a premise for glucose to suppress morphine withdrawal jumping. In addition, intraperitoneal injection of D-glucose (200, 500 and 1000 $\mathrm{mg} / \mathrm{kg}$ ) before morphine administration also significantly inhibited morphine withdrawal jumping in acute morphinetreated mice (data not shown). It is likely that certain metabolites of glucose may exert an inhibitory effect on the 
A

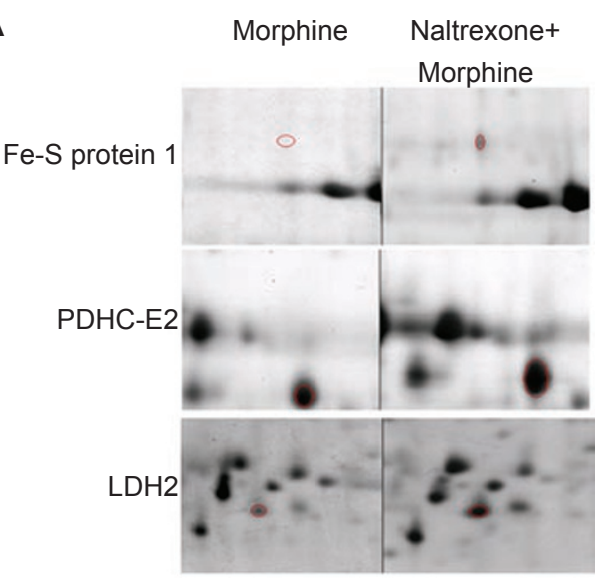

B

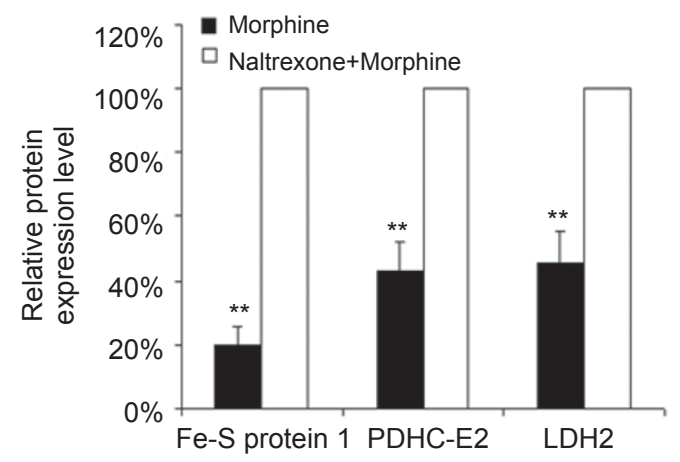

Figure 3 Naltrexone reversed chronic morphine-induced downregulation of Fe-S protein 1 of NADH dehydrogenase, PDHC-E2 and LDH2. (A) 2-DE images of the hippocampal proteins from chronic morphine-, and chronic morphine plus naltrexone-treated mice. (B) Quantification of the alterations of protein expression between the two groups. Mice were treated with an increasing dose (from 20 to $100 \mathrm{mg} / \mathrm{kg}$, s.c.) of morphine alone or morphine in combination with naltrexone (4 mg/kg, i.p.) for 10 days. The hippocampus extracts from differentially treated mice were separated by 2-DE followed by silver staining. Proteins displaying altered levels were quantified using PD-Quest software. Data are presented as means \pm SEM of at least three independent experiments $(n=9)$. $* * p<$ 0.01 versus combination-treated mice.

A

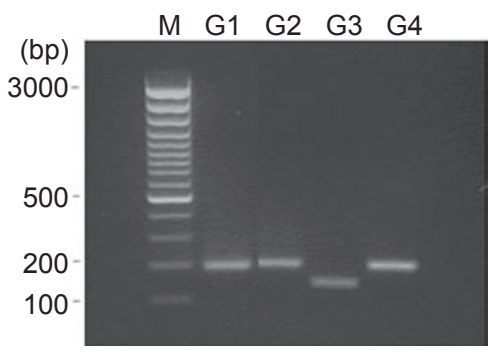

B

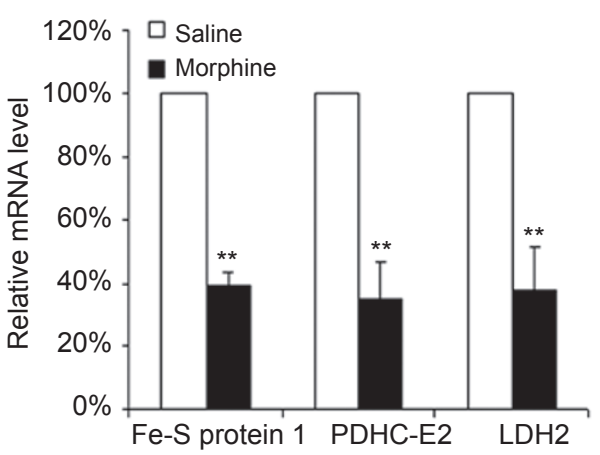

Figure 4 Downregulation of mRNAs corresponding to Fe-S protein 1 of NADH dehydrogenase, PDHC-E2 and LDH2 in the hippocampus of chronic morphine-treated mice. (A) Gel electrophoresis of PCR products from mouse hippocampal cDNA. A single band of the expected size for each gene was detected on agarose gel. G1, G2, G3 and G4 represent the RT-PCR products corresponding to mRNAs of LDH2 (192 bp), Fe-S protein 1 of NADH dehydrogenase (210 bp), PDHC-E2 (141 bp) and $\beta$-actin (197 bp), respectively. The marker lane shows a ladder of 14 bands from 100 to $3000 \mathrm{bp}$ (lane1). (B) Fold of reduction of mRNAs of Fe-S protein 1 of NADH dehydrogenase, PDHC-E2 and LDH2 in the hippocampus from chronic morphine-treated mice. Data are presented as means \pm SEM of three independent experiments $(n=6)$. ** $p<0.01$ versus saline-treated mice.

development and/or expression morphine dependence and that the impairment of hippocampal glucose metabolism would thus contribute to morphine dependence.

Intraperitoneal injection of D-glucose suppressed memory impairment in acute but not in chronic morphine-treated mice

Opioid dependence and learning and memory impairment have been proposed to share common molecular and cellular bases [9]. We thus examined the effect of glucose injection on memory impairment induced by acute or chronic morphine treatment. Since systemic and central injection of D-glucose produces similar behaviour effects [37] and peripheral glucose injection can increase ATP levels in the hippocampus (Figure 5), we administered D-glucose to mice by intraperitoneal injection. In agreement with previous studies [7, 8], acute and chronic exposure of mice to morphine impaired their performance in Morris water maze 

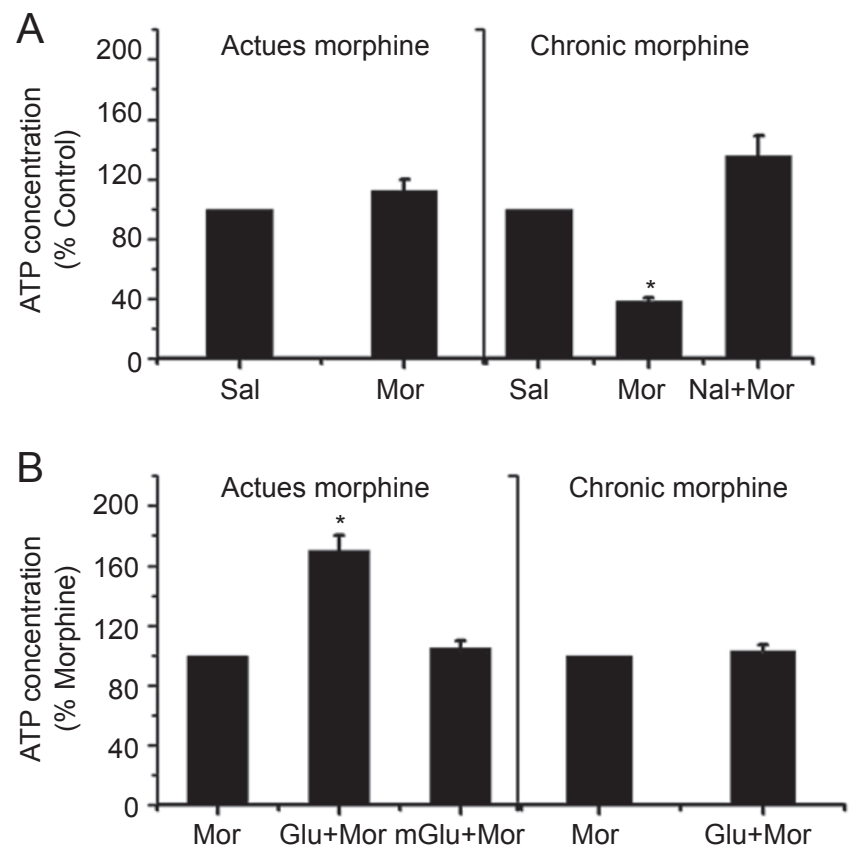

Figure 5 Reduction of ATP levels and impairment of glucose metabolism in the hippocampus derived from mice chronically treated with morphine. (A), Decrease of the hippocampal ATP levels by chronic but not acute morphine treatment and reversal of the chronic morphine effect by concomitant administration of naltrexone. (B), Increase of the hippocampal ATP levels by intraperitoneal injection of D-glucose $(200 \mathrm{mg} / \mathrm{kg}$, i.p.) in acute morphine-treated but not in chronic morphine-treated mice. Mice were treated either acutely with a single dose of morphine (100 mg/kg, s.c.) or chronically with an increasing dose of morphine (s.c.) alone or in combination with naltrexone (4 mg/kg, i.p.) for 10 days. ATP levels in the hippocampus from differentially treated mice were measured as described in Materials and Methods. Data are presented as means \pm SEM of at least three independent experiments $(n=6)$. ${ }^{*} p<0.05$ versus saline-treated mice (A) or versus acute morphine-treated mice without glucose injection (B). Sal: saline; Mor: morphine; Glu: D-glucose; mGlu: 3-O-methyl-glucose; Nal: naltrexone.

task. As shown in Figure 7, acute exposure of mice to morphine at the single dose of $10 \mathrm{mg} / \mathrm{kg}$ significantly prolonged the escape latency. Injection of D-glucose (500 mg/kg, i.p.) but not 3-O-methyl-glucose before morphine administration markedly shortened the escape latency. Consecutive exposure of mice to an escalating dose of morphine for 10 days also significantly prolonged their escape latency. However, in contrast to the effect of glucose on acute morphine-induced memory deficits, injection of D-glucose (500 $\mathrm{mg} / \mathrm{kg}$, i.p.) before final morphine injection failed to shorten the escape latency in chronic morphine-treated mice (Figure 7). The failure to alleviate morphine-induced memory impairment by glucose in chronic morphine-treated mice and by 3-O-methyl-glucose in acute morphine-treated mice suggests that glucose metabolism appears to be necessary for its antagonism of morphine-induced memory deficits. The observed latency difference between morphine-treated and control mice could not be explained by the effect of morphine on motor because there was no significant difference between saline- and morphine-treated mice in their swimming ability and visual discrimination for performing the task (data not shown).

\section{Discussion}

With proteomic analysis we found that chronic exposure to morphine resulted in a significant downregulation of the levels of Fe-S protein 1 of NADH dehydrogenase, PDHC$\mathrm{E} 2$ and $\mathrm{LDH} 2$ in the hippocampus. The finding was further confirmed by reduced expression of the corresponding mRNAs for these proteins and by pronounced reduction of ATP levels in the hippocampus of chronic morphine-treated mice. More importantly, our findings provide the first evidence showing that impairment of glucose metabolism in the hippocampus, as a result of reduced expression of these three proteins, was involved in the development of morphine withdrawal jumping and memory impairment.

Fe-S protein 1 of NADH dehydrogenase, PDHC-E2 and $\mathrm{LDH} 2$ are important enzymes or coenzyme for energy metabolism. Fe-S protein 1 is the coenzyme of NADH dehydrogenase, playing a key role in the transport of electrons from NADH to ubiquinone in the respiratory chain for ATP production. As one of the three enzymes of the pyruvate dehydrogenase complex, PDHC-E2 is necessary for the conversion of pyruvate to acetyl-CoA for the TCA cycle and serves as the bridge linking glycolysis and the TCA cycle in glucose metabolism. LDH2, a key enzyme of glycolysis, catalyses the reduction of pyruvate by NADH to form lactate, enabling the regeneration of $\mathrm{NAD}^{+}$to help fulfil the energy demand from glycolysis. Hence, downregulation of these proteins would result in impairment of energy metabolism and decrease of ATP production. This is supported by the fact that significantly lower ATP levels and an impaired ability to covert glucose to ATP were observed in the hippocampus of chronic morphine-treated mice. Our findings also offer a possible explanation for previous reports showing reduction of metabolic enzyme activities and increase of serum glucose levels in human and rodents upon chronic exposure to opiates [19, 20, 21, 38].

Both acute and chronic exposures to morphine lead to dependence [2-4]. Morphine dependence is manifested by characteristic withdrawal syndrome of multiple aversive behavioural signs. Among these withdrawal behaviours, jumping is widely considered as the most sensitive and reliable index and is commonly used to test opiate de- 
A
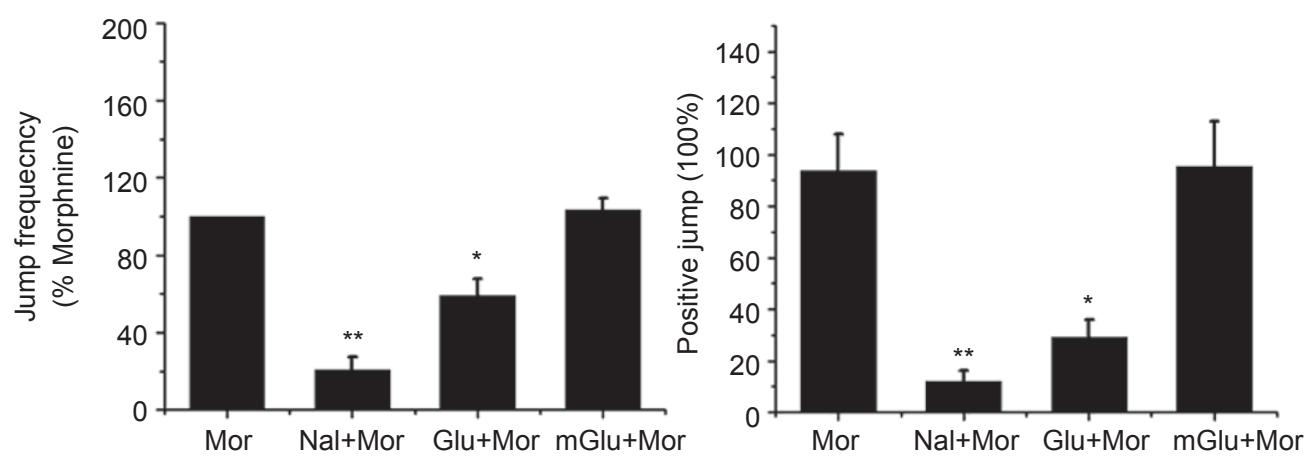

B
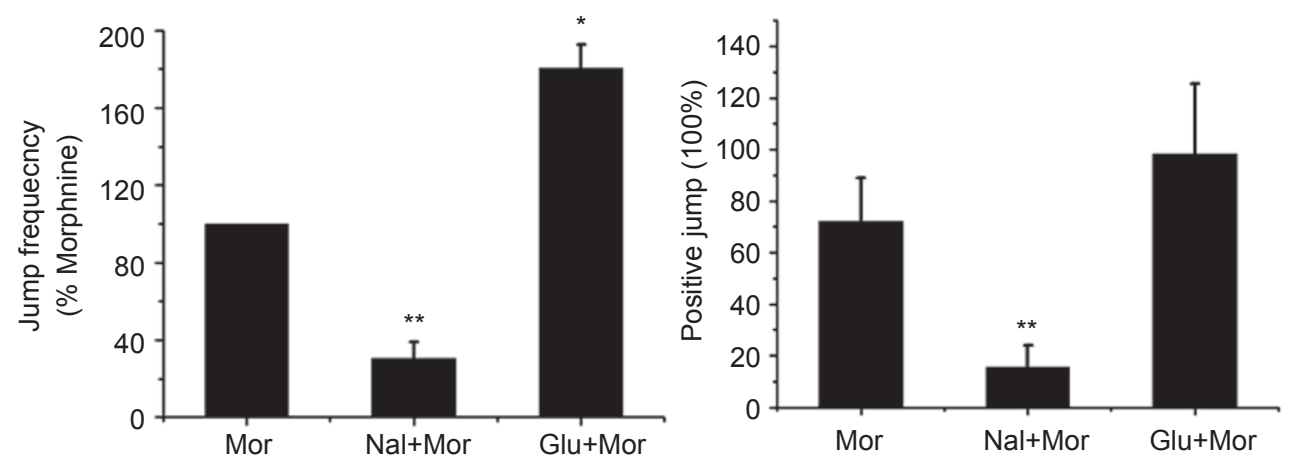

Figure 6 Effect of D-glucose on naloxone-precipitated morphine withdrawal in acute and chronic morphine-treated mice. (A) Inhibition of naloxone-precipitated morphine withdrawal jumping by administration of D-glucose but not by 3-O-methyl-glucose in acute morphine-treated mice. (B) Failure of suppression of naloxone-precipitated withdrawal jumping by D-glucose in chronic morphinetreated mice. Mice were treated either acutely with a single dose of morphine ( $100 \mathrm{mg} / \mathrm{kg}$, s.c.) or chronically with an increasing dose of morphine (s.c.) alone or in combination with naltrexone $(4 \mathrm{mg} / \mathrm{kg}$, i.p.) for 10 days. D-glucose or 3-O-methyl-glucose (8 nmol per side) was injected intrahippocampally before morphine (acute) or final morphine administration (chronic), followed by precipitation with naloxone ( $2 \mathrm{mg} / \mathrm{kg}$, i.p.). Withdrawal jumping was detected as described in Materials and Methods. Data are presented as means \pm SEM of at least three independent experiments $(n=10) .{ }^{*} p<0.05,{ }^{*} p<0.01$ versus acute morphine-treated mice (A) or versus chronic morphine-treated mice (B). Mor: morphine; Nal: naltrexone; Glu: glucose; mGlu: 3-O-methyl-glucose.

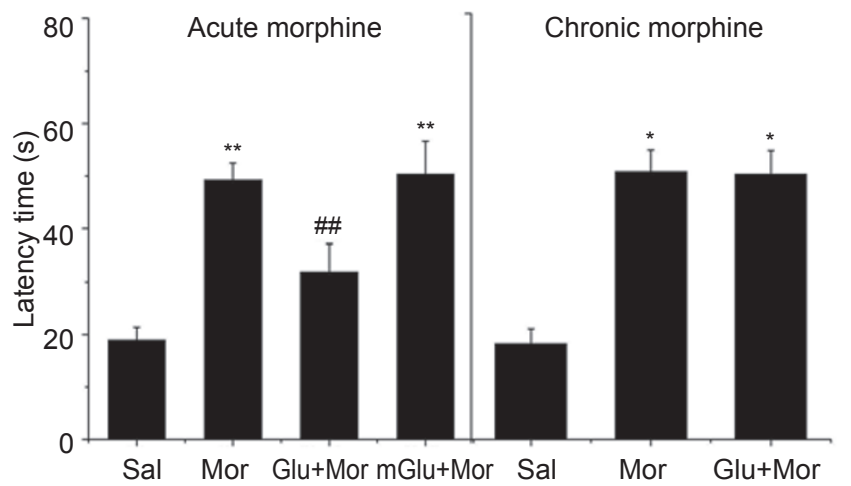

pendence state of the rodents (especially in mice) [2]. Our present study demonstrated that intrahippocampal or intraperitoneal injection of glucose before morphine administration significantly suppressed naloxone-precipitated
Figure 7 Improvement of acute but not chronic morphine treatment-induced memory deficits by D-glucose. Mice were treated either acutely with a single dose of morphine $(10 \mathrm{mg} / \mathrm{kg}$, s.c.) or chronically with morphine for 10 days. Escape latency of each mouse was recorded 20 min after morphine administration with the Morris water maze test as described in Materials and Methods. D-glucose or 3-O-methyl-glucose $(500 \mathrm{mg} / \mathrm{kg})$ was given by intraperitoneal injection before morphine (acute group) or final morphine administration (chronic group). Data are presented as means $\pm \operatorname{SEM}(n=$ 12). ${ }^{* *} p<0.01$ versus the saline group, ${ }^{\#} p<0.01$ versus the acute morphine group, ${ }^{*} p<0.05$ versus the saline group. Mor: morphine; Nal: naltrexone; Glu: glucose; mGlu: 3-O-methyl-glucose.

morphine withdrawal jumping in acute morphine-treated, but not in chronic morphine-treated mice, suggesting that glucose metabolism is necessary for its antagonism of morphine withdrawal jumping and this antagonism may 
be mediated by its metabolites. Indeed, ATP and its metabolites such as adenosine have been reported to suppress naloxone-precipitated morphine withdrawal symptoms $[39,40]$. The notion is also supported by the observation that intraperitoneal or intrahippocampal injection of the non-metabolizable sugar, 3-O-methyl-glucose, failed to suppress naloxone-precipitated withdrawal jumping in acute single morphine-treated mice. The different effects of glucose on morphine withdrawal jumping in acute and chronic morphine-treated mice may be attributed to the distinct downregulation of the three energy metabolism related proteins in chronic morphine-treated mice. Due to the downregulation of these proteins in the hippocampus of chronic morphine-treated mice, conversion of glucose to ATP and other metabolites would be impaired, and as a result it fails to inhibit morphine withdrawal jumping in these animals. Our results suggest that downregulation of the three proteins associated with energy metabolism in the hippocampus is involved in morphine dependence. This notion was further strengthened by the observation that preventing the downregulation of these three proteins by concomitant use of naltrexone during chronic morphine treatment also prevented morphine withdrawal jumping in these mice.

The Morris water maze task has been established as a useful behavioural test for spatial learning associated with the hippocampal function [41]. Consistent with previous studies [7, 42], our results showed that glucose suppressed acute morphine-induced impairment of learning and memory, whereas it failed to alleviate learning and memory impairment induced by chronic morphine treatment. The suppressive effect of glucose on acute morphine-induced withdrawal jumping and impairment of learning and memory suggests that common molecular and cellular events might be involved in the development or expression of these symptoms following exposure to morphine, and that alteration of glucose metabolism may be involved in the initiation of these molecular and cellular events.

One of the possible explanations for glucose suppression of morphine withdrawal jumping and memory impairment in acute morphine-treated mice is that certain metabolites or intermediate metabolites of glucose may exert an inhibitory effect on morphine-induced dependence and memory impairment. These metabolites or intermediate metabolites might either act as substrates, augmenting the synthesis of certain neurotransmitters such as acetylcholine, or act as neurotransmitters or neuromodulators, modulating the release of certain neurotransmitters (e.g., glutamate, GABA, dopamine, acetylcholine and noradrenaline). It is well established that acetylcholine is crucially involved in modulation of learning and memory [10]. It has also been shown that the attenuation of central cholinergic activity is involved in the expression of opioid withdrawal symptom $[43,44]$ and impairment of learning and memory [7]. Morphine has been shown to inhibit hippocampal acetylcholine release $[45,46]$. Glucose, administrated peripherally or intrahippocampally, could enhance hippocampal acetylcholine release $[47,48]$ by promoting the synthesis of acetylcholine through increasing the levels of acetyl-CoA, a precursor of acetylcholine [37].

Neurotransmitters such as glutamate and GABA play a crucial role in the development and/or expression of opioid dependence $[49,50]$. In the hippocampus, ATP and its metabolite adenosine have been shown to play an important role in modulation of glutamate and GABA release [5153]. Chronic exposure to opioids such as morphine might result in increment of glutamate release and decrement of GABA release through alteration of ATP and adenosine production in the hippocampus, as a result of impairment of glucose metabolism, thereby leading to the development of opioid dependence. In support of this notion, substantial evidence shows that NMDA receptor antagonists and $\mathrm{GABA}_{\mathrm{B}}$ receptor agonists prevent the development of opioid dependence and suppress opioid withdrawal signs $[49,50]$. Meanwhile, accumulating evidence demonstrates that increase of extracellular adenosine levels by adenosine kinase inhibitor and activation of both $\mathrm{A}_{1}$ and $\mathrm{A}_{2 \mathrm{~A}}$ receptors by their selective agonists attenuate the incidence of some of the morphine withdrawal signs, such as jumping, wetdog shakes and diarrhoea, whereas antagonists exacerbate the symptoms [40, 54].

In summary, the results of this study suggest that reduced expression of three energy metabolism enzymes and impaired glucose metabolism in the hippocampus of chronic morphine-treated mice were involved in the development and/or expression of the behavioural abnormalities associated with dependence and memory deficits. The effect of glucose on morphine withdrawal jumping is similar to that on memory impairment in acute morphine-treated mice, supporting that morphine-induced memory impairment and dependence may share common molecular and cellular mechanisms. Changes in certain glucose metabolites might be involved in the initiation of these molecular and cellular events. Our results here reveal a new aspect of the mechanisms of opiate dependence. Further studies are necessary to ascertain the metabolites and to elucidate the mechanisms underlying their effects.

\section{Acknowledgments}

We thank Dr Boja Emily S (NHLBI, NIH, USA) for expert technical assistance in mass spectrometry analyses, and our colleagues Drs Bin Lu, Zhao-Qiu Wu for helpful comments. This work was supported by a National Basic 
Research Program grant from the Ministry of Science and Technology of China (G2003CB515401), National Science Fund for Distinguished Young Scholar from the National Natural Science Foundation of China (30425002) and a fund supported by the " 100 Talents Project" of Chinese Academy of Sciences (J-G Liu).

\section{References}

1 Nestler EJ. Under siege: the brain on opiates. Neuron 1996; 16:897-900.

2 Kest B, Palmese CA, Hopkins E, Adler M, Juni A, Mogil S. Naloxone-precipitated withdrawal jumping in 11 inbred mouse strains: evidence for common genetic mechanisms in acute and chronic morphine physical dependence. Neuroscience 2002; 115:463-469.

3 Mclemore GL, Kest B, Inturrisi CE. The effects of LY293558, an AMPA receptor antagonist, on acute and chronic morphine dependence. Brain Res 1997; 778:120-126.

4 Schulteis G, Heyser CH, Koob GF. Opiate withdrawal signs precipitated by naloxone following a single exposure to morphine: potentiation with a second morphine exposure. Psychopharmacology (Berl) 1997; 129:6-65.

5 Guerra D, Sole J, Tobena A. Neuropsychological performance in opiate addicts after rapid detoxification. Drug Alcohol Depend 1987; 20:261-270.

6 Stefani MR, Nicholson GM, Gold PE. ATP-sensitive potassium channel blockade enhances spontaneous alteration performance in the rat: a potential mechanism for glucose-mediated memory enhancement. Neuroscience 1999; 93:557-563.

7 Li Z, Wu CF, Pei G, Xu NJ. Reversal of morphine-induced memory impairment in mice by withdrawal in Morris water maze: possible involvement of cholinergic system. Pharmacol Biochem Behav 2001; 68:507-513.

$8 \mathrm{Pu}$ L, Bao GB, Xu NJ, Ma L, Pei G. Hippocampal long-term potentiation is reduced by chronic opiate treatment and can be restored by re-exposure to opiates. J Neurosci 2002; 22:19141921.

9 Nestler EJ. Common molecular and cellular substrates of addiction and memory. Neurobiol Learn Mem 2002; 78:637-647.

10 Everitt BJ, Robbins TW. Central cholinergic systems and cognition. Annu Rev Psychol 1997; 48:649-684.

11 Rezayof A, Zarrindast MR, Sahraei H, Haeri-Rohani A. Involvement of dopamine receptors of the dorsal hippocampus on the acquisition and expression of morphine-induced place preference in rats. J Psychopharmacol 2003; 17:415-423.

12 Rezayof A, Zatali H, Haeri-Rohani A, Zarrindast MR. Dorsal hippocampal muscarinic and nicotinic receptors are involved in mediating morphine reward. Behav Brain Res 2006; 166:281290.

13 Zarrindast MR, Massoudi R, Sepehri H, Rezayof A. Involvement of $\mathrm{GABA}(\mathrm{B})$ receptors of the dorsal hippocampus on the acquisition and expression of morphine-induced place preference in rats. Physiol Behav 2006; 87:31-38.

14 Done C, Silverstone P, Sharp T. Effect of naloxone-precipitated morphine withdrawal on noradrenaline release in rat hippocampus in vivo. Eur J Pharmacol 1992; 215:333-336.

15 Fan GH, Wang LZ, Qiu HC, Ma L, Pei G. Inhibition of calcium/ calmodulin-dependent protein kinase II in rat hippocampus attenuates morphine tolerance and dependence. Mol Pharmacol 1999; 56:39-45.

$16 \mathrm{Lu} \mathrm{L}$, Zeng S, Liu D, Geng X. Inhibition of the amygdala and hippocampal calcium/calmodulin-dependent protein kinase II attenuates the dependence and relapse to morphine differently in rats. Neurosci Lett 2000; 291:191-195.

17 Vorel SR, Liu X, Hayes RJ, Spector JA, Gardner EL. Relapse to cocaine-seeking after hippocampal theta burst stimulation. Science 2001; 292:1175-1178.

18 Kalant H. Problems in the search for mechanisms of tolerance. Alcohol Alcohol Suppl 1993; 2:1-8.

19 Dodge PW, Takemori AE. Effects of morphine, nalorphine and pentobarbital alone and combination on cerebral glycolytic substrates and cofactors of rats in vivo. Biochem Pharmacol 1972; 21:287-294.

20 Sherman AD, Mitchell CL. Effects of morphine and pain on brain intermediary metabolism. Neuropharmacology 1972; 11:871877.

21 Sood PP, Mohanakumar KP. Changes in succinic dehydrogenase activity in the central nervous system of mice during morphine dependence development, withdrawal and naloxone treatment. Clin Physiol Biochem 1985; 3:193-198.

22 Stone WS, Rudd RJ, Gold PE. Glucose and physostigmine effects on morphine- and amphetamine-induced increase in locomotor activity in mice. Behav Neural Biol 1990; 54:146-155.

23 Ragozzino ME, Gold PE. Glucose injections into the medial septum reverse the effects of intraseptal morphine infusions on hippocampal acetylcholine output and memory. Neuroscience 1995; 68:981-988.

24 Talley CP, Arankowsky-Sandoval G, McCarty R, Gold PE. Attenuation of morphine-induced behavioral changes in rodents by D- and L-glucose. Neurobiol Learn Mem 1999; 71:62-79.

25 Jafari MR, Zarrindast MR, Djahanguiri B. Effects of different doses of glucose and insulin on morphine state-dependent memory of passive avoidance in mice. Psychopharmacology 2004; 175:457-462.

26 Shook JE, Kachur JF, Brase DA, Dewey WL. Morphine dependence and diabetes. II. Alteration of normorphine potency in the guinea-pig ileum and mouse vas deferens and of ileal morphine dependence by changes in glucose concentration. J Pharmacol Exp Ther 1986; 237:848-852.

27 Akunne HC, Soliman KF. Hyperglycemic suppression of morphine withdrawal signs in the rat. Psychopharmacol 1988; 96:1-6.

28 Kamei J, Ohsawa M, Saitoh A, et al. Modification of mu-opioid agonist-induced locomotor activity and development of morphine dependence by diabetes. J Pharmacol Exp Ther 1995; 274:700706.

29 McClung CA, Nestler EJ, Zachariou V. Regulation of gene expression by chronic morphine and morphine withdrawal in the locus ceruleus and ventral tegmental area. J Neurosci 2005; 25:6005-6015.

30 Guo GW, He Y, Jin WQ, Zou Y, Zhu YC, Chi ZQ. Comparison of physical dependence of ohmefentanyl stereoisomers in mice. Life Sci 2000; 67:113-120.

31 Paxinos G, Franklin KBJ. The mouse brain in stereotaxic coordinates. 2nd Edition. San Diego: :Academic Press, 2004.

32 Ragozzino ME, Parker ME, Gold PE. Spontaneous alteration 
and inhibitory avoidance impairments with morphine injections into the medical septum. Attenuation by glucose administration. Brain Res 1992; 597:241-249.

33 Langen H, Roder D, Juranville JF, Fountoulakis M. Effect of protein application mode and acrylamide concentration on the resolution of protein spots separated by two-dimensional gel electrophoresis. Electrophoresis 1997; 18:2085-2090.

34 Yan JX, Wait R, Berkelman T, et al. A modified silver staining protocol for visualization of proteins compatible with matrixassisted laser desorption/ionization and electrospray ionizationmass spectrometry. Electrophoresis 2000; 21:3666-3672.

35 Piubelli C, Galvani M, Hamdan M, Domenici E, Righetti PG. Proteome analysis of rat polymorphonuclear leukocytes: a two-dimensional electrophoresis/mass spectrometry approach. Electrophoresis 2002; 23:298-310.

36 Perkins DN, Pappin DJ, Creasy DM, Cottrell JS. Probabilitybased protein identification by searching sequence databases using mass spectrometry data. Electrophoresis 1999; 20:35513567.

37 Messier C. Glucose improvement of memory: a review. Eur J Pharmacol 2004; 490:33-57.

38 Sadava D, Alonso D, Hong H, Pettit-Barrett DP. Effects of methadone addiction on glucose metabolism in rats. Gen Pharmacol 1997; 28:27-29.

39 Gomaa AA, Moustafa A, Farghali AA. Adenosine triphosphate blocks opiate withdrawal symptoms in rats and mice. Pharmacol Toxicol 1989; 64:111-115.

40 Kaplan GB, Coyle TS. Adenosine kinase inhibitors attenuate opiate withdrawal via adenosine receptor activation. Eur J Pharmacol 1998; 362:1-8.

41 Morris RG, Anderson E, Lynch GS. Selective impairment of learning and blockade of long-term potentiation by an $\mathrm{N}$-methylD-aspartate receptor antagonist, AP5. Nature 1986; 319:774776.

42 Ragozzino ME, Gold PE. Glucose injections into the medial septum reverse the effects of intraseptal morphine infusions on hippocampal acetylcholine output and memory. Neuroscience 1995; 68:981-988.

43 Sharif SI, eL-Kadi AO. The role of cholinergic systems in the expression of morphine withdrawal. Neurosci Res 1996; 25:155160.

44 Buccafusco JJ, Zhang LC, Shuster LC, Jonnala RR, Gattu M. Prevention of precipitated withdrawal symptoms by activating central cholinergic systems during a dependence-producing schedule of morphine in rats. Brain Res 2000; 852:76-83.

45 Walker DL, McGlynn T, Grey C, Ragozzino M, Gold PE. Naloxone modulates the behavioral effects of cholinergic agonists and antagonists. Psychopharmacology 1991; 105:57-62.

46 Ragozzino ME, Wenk GL, Gold PE. Glucose attenuates a morphine-induced decrease in hippocampal acetylcholine output: an in vivo microdialysis study in rats. Brain Res 1994; 655:77-82.

47 Ragozzino ME, Unick KE, Gold PE. Hippocampal acetylcholine release during memory testing in rats: augmentation by glucose. Proc Natl Acad Sci USA 1996; 93:4693-4698.

48 Ragozzino ME, Pal SN, Unick K, Stefani MR, Gold PE. Modulation of hippocampal acetylcholine release and spontaneous alternation scores by intrahippocampal glucose injections. J Neurosci 1998; 18:1595-1601.

49 Trujillo KA, Akil H. Excitatory amino acids and drugs of abuse: a role for $N$-methyl-D-aspartate receptors in drug tolerance, sensitization and physical dependence. Drug Alcohol Depend 1995; 38:139-154.

50 Cousins MS, Roberts DC, de Wit H. GABA(B) receptor agonists for the treatment of drug addiction: a review of recent findings. Drug Alcohol Depend 2002; 65:209-220.

51 Cunha RA, Ribeiro JA. Purinergic modulation of [(3)H]GABA release from rat hippocampal nerve terminals. Neuropharmacology 2000; 39:1156-1167.

52 Mendoza-Fernandez V, Andrew RD, Barajas-Lopez C. ATP inhibits glutamate synaptic release by acting at $\mathrm{P} 2 \mathrm{Y}$ receptors in pyramidal neurons of hippocampal slices. J Pharmacol Exp Ther 2000; 293:172-179.

53 Masino SA, Diao L, Illes P, et al. Modulation of hippocampal glutamatergic transmission by ATP is dependent on adenosine A1 receptors. J Pharmacol Exp Ther 2002; 303:356-363.

54 Salem A, Hope W. Effect of adenosine receptor agonists and antagonists on the expression of opiate withdrawal in rats. Pharmacol Biochem Behav 1997; 57:671-679. 